\title{
JUSTIÇA DO TRABALHO E A CONQUISTA DOS DIREITOS: o direito de conhecer a história da Justiça do Trabalho
}

Alisson Droppa

O Memorial da Justiça do Trabalho no Rio Grande do Sul é uma iniciativa do Tribunal Regional do Trabalho da 4ạ Região - TRT, que desde 2004 auxilia na preservação e disponibilização para a pesquisa da documentação preservada pela referida instituição. A singularidade da iniciativa do TRT é de suma importância para a comunidade acadêmica, pois que abriu suas "portas" à Comunidade, seja do ponto de vista da pesquisa ou pelo envolvimento de toda a comunidade do Rio Grande do Sul em cursos de extensão sobre Direito do Trabalho, reafirmando que essa é uma Instituição que tem história, e que essa história é a história de cada um dos que estiveram incumbidos do "fazer" / do "produzir" a Justiça do Trabalho ao longo desses 78 anos. Eric Hobsbawm afirma:

\begin{abstract}
Digam os filósofos o que quiserem, os "direitos" não são abstratos, universais e imutáveis. Eles existem nas mentes de homens e mulheres como partes de conjuntos especiais de convicções sobre a natureza da sociedade humana e sobre a ordenação das relações entre os seres humanos dentro dela: um modelo de ordem social e política, um modelo de moralidade e justiça. ${ }^{1}$
\end{abstract}

Uma das vias de acesso à história da Justiça do Trabalho e a da luta dos trabalhadores pela efetivação de direitos - são as reclamações apresentadas perante as antigas Juntas de Conciliação e Julgamento, hoje Varas do Trabalho, e perante os Tribunais do Trabalho. Essas fontes, esses documentos, contam a história das lutas sociais brasileiras e da construção do Direito e da Justiça do Trabalho no Brasil. Muitos desses processos foram eliminados ${ }^{2}$. Os poucos que sobraram compõem acervos de inegável valor histórico e têm sido fontes primárias relevantes para pesquisadores das mais diversas áreas do conhecimento.

\footnotetext{
* Doutorando em História Social pela Universidade Estadual de Campinas, mestre em Estudos Histórico Latino Americanos pela Universidade do Vale do Rio dos Sinos.

${ }^{1}$ HOBSBAWN, Eric J. O Mundo do Trabalho. Rio de Janeiro: Paz e Terra, 1987, 419p.

${ }^{2}$ No estado do Paraná, por exemplo, restam cerca de 70 mil processos de 1932 a 2000.
} 
Nessa perspectiva, o texto do historiador Fernando Teixeira da Silva, Nem crematório de fontes nem museu de curiosidades: por que preservar os documentos da Justiça do Trabalho $^{3}$, recorre à importância dos processos trabalhistas como fonte para a História. Corrobora a possibilidade de pesquisar a história do trabalho ou das instituições relacionadas aos trabalhadores por meio de autos trabalhistas, que contêm, além de informações sobre as lutas coletivas e individuais, aspectos da própria história da instituição na qual foram ajuizados.

Como mencionei anteriormente, os documentos da Justiça do Trabalho são fontes essenciais para a pesquisa histórica. Mas devo enfatizar que a sua preservação é assunto novo e polêmico na Justiça do Trabalho. A compreensão de sua profundidade e relevância tem esbarrado, por vezes, no argumento da falta de espaço físico para a guarda adequada. ${ }^{4}$ Todavia, o que quero ressaltar com esse pequeno texto, é um exemplo do que pode ser encontrado em um amarfanhado de "papéis velhos". Além dos processos judiciais, existem outros documentos com grande importância, que merecem ser pesquisados. Um bom exemplo são as fichas de tramitação dos processos coletivos.

Essas fichas não foram produzidas por grandes juristas, por grandes advogados, ou, numa linguagem mais acadêmica, pelos operadores do direito. Elas eram preenchidas por servidores da Justiça do Trabalho, que ao receberem as reivindicações dos Sindicatos dos empregados ou dos empregadores (seja um dissídio coletivo, uma revisão de dissídio coletivo ou um pedido de homologação), efetuavam o registro no referido documento, no qual seria anotado todo o trâmite que fosse considerado relevante.

Essas fichas estão hoje sob responsabilidade do Setor de Encaminhamento do TRT. Sua descoberta, proporcionada pelo auxílio do Servidor Elton Decker, que prontamente acionou os caminhos internos do Tribunal (por meio de Memorandos), e contou com o apoio e total profissionalismo da Diretora do Serviço de Cadastramento, que facilitou a consulta aos documentos.

De posse dessa "costela uruguaia", como diriam os missioneiros, entre os quais me incluo, dediquei-me a entender a referida fonte e a buscar explorar o que ela poderia me fornecer como pesquisador. Assim, percebi que essas fichas, não mais utilizadas, eram compostas dos seguintes campos: Reclamante, Reclamada, Assunto (tipo de processo), data, Movimentação e Observações, divididas em linhas e colunas. Cada uma das linhas imprimia data, movimentação e a observação do servidor. Nas observações do servidor eram descritos os encaminhamentos, Relatores, Revisores, Instâncias percorridas e os resultados obtidos, de forma "genérica". Poderia elencar um rol interminável de possibilidades de pesquisa na referida fonte. Vamos a alguns:

\footnotetext{
${ }^{3}$ SILVA, Fernando Teixeira da. Nem crematório de fontes nem museu de curiosidades: por que preservar os documentos da Justiça do Trabalho. In: BIAVASCHI, Magda Barros; MIRANDA, Maria Guilhermina (Org.). Memória e preservação de documentos: direito do cidadão. São Paulo: LTr, 2007.

${ }^{4}$ A guarda adequada dos documentos judiciais diz respeito a sua conservação hígida, que não comprometa - o documento - de forma alguma o suporte da informação, para fins de pesquisa e produção de prova.
} 
Em primeiro lugar, foi possível verificar o aumento no número de dissídios coletivos ajuizados e julgados pelo TRT4 no período de 1946 (incorporação da Justiça do Trabalho ao Poder Judiciário) até 1964. Considerados apenas os processos ajuizados por sindicatos do município de Porto Alegre em 1946, foram ajuizados 14 dissídios; 18 anos depois, quando o Tribunal completava sua maior idade, foram ajuizados 74 processos. Cabe mencionar que nessa trajetória o ano de 1958 é singular, pois inaugura uma curva ascendente no número de processos, culminando no pico de 1964.

Os significados desses números merecem profunda e ampla pesquisa no que diz respeito ao que motivou os sindicatos a visualizarem na Justiça do Trabalho um espaço legítimo para a resolução dos conflitos. É uma das questões que pretendo resolver ao longo de minha tese de doutoramento, em curso no Centro de Pesquisa em História Social da Cultura do Instituto de Filosofia e Ciências Humanas/UNICAMP.

Como é verdade que o número de estabelecimentos industriais e de sindicatos vinha aumentado desde 1943, conforme constatado pela pesquisadora Magda Barros Biavaschi ${ }^{5}$, a Justiça do Trabalho também se ampliava ao longo do tempo. De apenas quatro Juntas em 1946, passou a contar 22 somente no Rio Grande do Sul, sendo seis unicamente em Porto Alegre, no ano de 1964, o que pode ser justificado pelo aumento na demanda por julgamentos.

Esses números são vazios e sem significados propriamente ditos quando não contextualizados com a situação política do Rio Grande do Sul do período. A vitória do PTB para as eleições de 1958, tendo como representante eleito o governador Leonel Brizola, é um fato muito importante para a história do trabalho, da classe trabalhadora e empresarial e, consequentemente, para a Justiça do Trabalho.

A política de Brizola de governar com apoio dos sindicatos e mobilizar a classe trabalhadora para reivindicações diante do Governo Federal, segundo João Marcelo Pereira dos Santos, trouxe como consequência a transferência de responsabilidade do Estado para a Federação, contribuindo para o projeto brizolista.

Ao afirmar que as reivindicações da classe trabalhadora gaúcha no período de 1958 a 1963 estavam atreladas ao governo estadual, Santos me faz pensar se os trabalhadores não tiveram melhorias em suas condições de vida no período, e mais, como teria sido o papel da Justiça do Trabalho nessa conjuntura. Afinal, como a Justiça do Trabalho julgava as reclamatórias?

Os processos ajuizados pelos Sindicatos Patronais de Porto Alegre em 1958 representaram 19,51\% do total. Em regra, nesses casos, a categoria econômica buscava a homologação de acordos. Nos demais $89,49 \%$, os Sindicatos Profissionais ajuizaram as ações, buscando em $57,57 \%$ a homologação de acordos predefinidos. ${ }^{6}$ Esse dado pode demonstrar

\footnotetext{
${ }^{5}$ BIAVASCHI, Magda Barros. O Direito do Trabalho 1930-1942: a construção do sujeito de direitos trabalhista. LTR: São Paulo, 2007.

${ }^{6} \mathrm{O}$ termo predefinido se refere ao caso em que os sindicatos patronais e dos empregados chegavam a acordos extrajudiciais, encaminhando à Justiça do Trabalho apenas a homologação do acordo.
} 
preliminarmente que os trabalhadores mostravam sua força fora do âmbito da Justiça, mas a consideravam uma instância legítima, pois mesmo conseguindo elaborar acordos extraTribunal, ajuizavam ações homologatórias conforme determinava a lei.

O caso do Sindicato dos Trabalhadores em Energia Elétrica de Porto Alegre é um exemplo interessante. Conforme descreveu Santos em sua dissertação de mestrado, o encampamento da Companhia de Energia Elétrica Rio Grandense - CEERG pela Companhia Estadual de Energia Elétrica - CEEE em 1958 foi uma vitória preliminar do movimento sindical, mas que acabou por gerar um outro problema. Ao abrir o processo de Revisão de Dissídio Coletivo no referido ano, a diretoria sindical se viu pressionada pela diretoria da estatal a dissolver o Sindicato: os trabalhadores passariam a compor o quadro do funcionalismo público regido por Estatuto próprio.

Além disso, a diretoria da estatal preconizou um aumento salarial para aquele ano de apenas 15\%. Mas o Sindicato dos Trabalhadores mostrou sua força perante a sociedade e a Justiça do Trabalho. O Sindicato ajuizou ação de Revisão de Dissídio Coletivo: postulando aumento de $45 \%$ sobre os salários, com elevação do piso salarial de $\mathrm{Cr} \$ 1500,00$ e do teto a Cr\$ 6.000,00, apresentando, ainda, proposta de conciliação com um aumento de $35 \%$ dos salários e concessão de abono de Natal equivalente ao salário de um mês de trabalho. Assinou a inicial Jorge Alberto Campenatto - Presidente do Sindicato dos Trabalhadores em Energia Elétrica de Porto Alegre, em 3 dezembro de 1958.

Ao documento inicial, encaminhado pelo Sindicato à Justiça do Trabalho, foram agregados outros: encaminhamento à 18. a Delegacia Regional do Trabalho, de 3 de dezembro de 1958, assinado pelo Presidente da Comissão de Dissídios Coletivos da referida 18a Delegacia, datado de 4 de dezembro de 1958, e o protocolo do TRT4, de 9 de dezembro do mesmo ano.

O Presidente da Comissão de Dissídios Coletivos, Dr. João Zuchatto Sobrinho, fixou o dia 6 de dezembro de 1958 para audiência conciliatória. Nesta, não havendo acordo entre as partes, a Comissão de Conciliação encaminhou ao Tribunal um parecer sugerindo aumento de $27 \%$. Em relação ao abono de Natal, o parecer afirmou que não poderia haver a obrigatoriedade deste. No Tribunal, foi instaurado o Dissídio Coletivo. No seu julgamento, em 18 de dezembro de 1958, o Tribunal acatou o conteúdo do Parecer da Comissão de Dissídios Coletivos, acrescentando, nas cláusulas deferidas, abono de Natal correspondente a 16 dias de trabalho e um piso de $\mathrm{Cr} \$ 3.100,00$ e teto de $\mathrm{Cr} \$ 10.000,00$.

É interessante notar que restaram vencidos o Juiz Relator, Sebastião da Silva (representante classista dos empregados e o Juiz Dr. Carlos Barata Silva, sendo necessário voto de desempate do Presidente em exercício, Dr. Dilermando Xavier Pôrto, o que demonstra o grau de debate que envolveu o tema. Cabe destacar que os Juízes togados eram tratados com o título de Doutores, demonstrando certa diferença com os classistas, tratados apenas como senhores.

Cabe uma investigação mais aprofundada desses casos. Cruzando com dados de outras categorias e com argumentações das partes envolvidas (empregados, empregadores 
e Justiça), no intuito de entender o poder da Justiça do Trabalho em construir a norma para as categorias em litígio, fixando, por exemplo, o percentual do reajuste salarial e o abono de Natal. Afinal, como demonstrado no caso dos eletricitários, num período de 12 dias, do encaminhamento do parecer da Delegacia Regional do Trabalho até o julgamento do acórdão pelo TRT4, houve alterações no entendimento do julgador, acrescentando-se o direito ao abono de Natal. O que poderia ter influenciado a modificação? Certamente a força política da Categoria Sindical, pressionando a sociedade e, consequentemente, a Justiça do Trabalho no sentido do acolhimento de suas reivindicações, com reflexos no ato de julgar.

Entender essa lógica é um exercício que precisa ser feito. Cabe mencionar que o processo aqui analisado foi "mutilado" pela técnica de desentranhamento de documentos, sendo necessário tentar buscar alternativas para resgatar a discussão como um todo. Somente uma pesquisa mais aprofundada determinará se isso é possível. 